\title{
Desenhando o campo da matemática: Aplicação DOS CONCEITOS DE PIERRE BOURDIEU NA EDUCAÇÃO MATEMÁTICA
}

Jose Vilani de FARIAS* Denise Silva VILELA*

RESUMO: A partir da teoria sociológica de Pierre Bourdieu e das pesquisas em Educação Matemática apresentamos, nesse artigo, uma interpretação da Matemática enquanto campo: com suas leis, agentes, capitais, disputas, gostos e distinções. Nosso objetivo foi desenhar o campo da matemática, a partir da análise de um Programa de mestrado profissional em matemática em rede nacional (Profmat). Esse programa foi idealizado e implantado pela Sociedade Brasileira de Matemática e pelo Instituto de Matemática Pura e Aplicada, instituições que, reconhecidas por desenvolver pesquisa de alto nível em matemática, não são reconhecidas no âmbito das pesquisas em formação de professores. A investigação sociológica, realizada mediante a elaboração da noção de campo, permitiu uma compreensão do Profmat como uma estratégia de valorização de uma prática Matemática e uma compreensão da Matemática enquanto um espaço hierarquizado de agentes em disputa pelo direito de definir o que é matemática e quem tem distinção suficiente para defini-la.

PALAVRAS-CHAVE: Campo da Matemática. Educação. Matemática acadêmica. Formação de Professores

Introdução

As obras do sociólogo francês Pierre Bourdieu começam a ter destaque no cenário brasileiro, principalmente no campo da Educação, a partir do final da década

\footnotetext{
* UFRN - Instituto Federal de Educação, Ciência e Tecnologia do Rio Grande do Norte. Canguaretama RN - Brasil. 59190-000 - vilani.farias@ifrn.edu.br. https://orcid.org/0000-0002-3411-3420.

** UFSCar - Universidade Federal de São Carlos. Departamento de Metodologia de Ensino. São Carlos, SP - Brasil. 13565-905 - denisevilela@ufscar.br. https://orcid.org/0000-0003-2973-1301.
} 
de 1970. Embora, segundo Catani, Catani e Pereira (2001), os primeiros textos de Bourdieu - dois artigos intitulados: Problemas do estruturalismo e Sociologia da juventude - traduzidos para o português, já circulassem no país desde 1968. A obra $A$ Reprodução, publicada no Brasil no ano de 1975, é uma das mais divulgadas, conhecidas e, talvez, a mais criticada, no país: "[...] a obra de Bourdieu, lida, sobretudo, a partir de A Reprodução, passa a ser objeto de controvérsias políticas no campo educacional brasileiro" (CATANI; CATANI; PEREIRA, 2001, p.66).

As críticas à A Reprodução, ou as controvérsias que giraram em torno desse livro se devem à abordagem feita ao sistema de ensino, e consequentemente, à escola, como um instrumento capaz de reproduzir as desigualdades sociais, num momento em que, segundo Gonçalves e Gonçalves (2011), estavam no auge as ideias de uma escola democrática e libertadora.

Alguns comentadores, como Maria Alice Nogueira, Cláudio Marques Martins Nogueira (2009) e Denice Bárbara Catani (2011) afirmam que essas críticas são frutos de uma leitura parcial e equivocada das obras de Bourdieu:

Obras como Os herdeiros, de 1964, e, sobretudo, A reprodução, de 1970, trouxeram-lhe notoriedade mundial. Esta última costuma ser tomada, aliás, de maneira equivocada, como a quinta-essência de sua teoria sociológica em Educação (NOGUEIRA; NOGUEIRA, 2009, p.49).

[...] no campo educacional, durante muito tempo, restringiu a leitura do autor ao livro $A$ reprodução, de forma quase exclusiva. As consequências dessa iniciação, aliás, vincada pelas próprias condições sócio-históricas brasileiras, são bastante conhecidas, [...] (CATANI, 2011, p.333).

Esses autores, por meio de seus trabalhos acadêmicos, ajudaram, não apenas a difundir as obras de Bourdieu no Brasil, mas a compreender melhor a educação na perspectiva desse sociólogo e a compreender essa proposta sociológica para pensar a educação. Escritos de Educação, organizado por Maria Alice Nogueira e Afrânio Mendes Catani (2001), é um desses trabalhos. Esse livro é uma coletânea de vários textos sobre educação, produzidos por Bourdieu, que, segundo os organizadores, é "uma seleção de alguns dos mais importantes escritos do autor em matéria de educação e de ensino, que ainda não estavam disponíveis em nosso país [...]" (NOGUEIRA; CATANI, 2001, p.7).

Com a divulgação das obras de Pierre Bourdieu e a produção de vários 
trabalhos de seus comentadores, começaram a surgir, no Brasil, diversas produções acadêmicas, principalmente em educação, que aplicaram os conceitos da teoria de Bourdieu. Alguns desses conceitos, como habitus, campo e capital, mostram-se potentes quando se pretende interpretar fenômenos sociais em diversas áreas do conhecimento.

Nesse trabalho comentarei a respeito da aplicação desses conceitos nas pesquisas em educação, especificamente nas que tratam da formação de professores e, de maneira mais detalhada, nas pesquisas que abordam a formação do professor de Matemática. Darei ênfase a uma pesquisa de Farias (2017) que, valendo-se do conceito de campo, interpreta a formação do professor de Matemática como uma estratégia de distinção e poder dentro do campo da Matemática.

\section{Aplicação dos conceitos de habitus, campo e capital em algumas pesquisas educacionais sobre a formação do professor}

Algumas pesquisas que estudam a formação docente o fazem com uma abordagem sociológica utilizando os conceitos da teoria de Bourdieu. O conceito de habitus é empregado por vários autores para interpretar determinados aspectos $\mathrm{e}$ fenômenos relacionados à formação do professor:

Sistemas de disposições duráveis, estruturas estruturadas predispostas a funcionar como estruturas estruturantes, isto é, como princípio gerador e estruturador das práticas e das representações que podem ser objetivamente "reguladas" e "regulares" sem ser produto da obediência a regras objetivamente adaptadas a seu fim sem supor a intenção consciente dos fins e o domínio expresso das operações necessárias para atingi-los e coletivamente orquestradas, sem ser $\mathrm{o}$ produto da ação organizadora de um regente (BOURDIEU, 2013b, p.53).

Entre tais pesquisas, notamos que esse conceito vem acompanhado por diferentes adjetivos: habitus profissional, habitus professoral, habitus docente, habitus acadêmico, habitus escolar, habitus disciplinar etc. Com essa adjetivação, os autores propõem uma análise das relações entre a formação recebida na academia, por ocasião da formação inicial, e a prática do professor ao chegar à escola.

Alguns desses autores destacam também as condições sociais que influenciam essa relação. Ou seja, como, por meio das disposições dos futuros professores é 
internalizada certa formação acadêmica, e como essa é incorporada ao seu trabalho em sala de aula? Em que medida as trajetórias escolares dos futuros professores modificam sua maneira de perceber a relação professor e aluno, a maneira de se perceber como professor e ainda a de perceber o aluno e o espaço escolar?

$\mathrm{Na}$ mesma linha de pesquisa, Lelis (2001) desenvolveu seu trabalho instigada por suas inquietações diante do discurso que aponta a prática do magistério como insuficiente e desqualificada. Tomando como ponto de partida esse discurso, buscou refletir sobre a identidade social do magistério. Identidade que, segundo a autora, é construída nas relações familiares, escolares e profissionais. Para sedimentar seu argumento, recorre ao conceito de habitus e acrescenta que a construção da identidade docente ocorre por meio de "processos invisíveis de constituição de habitus profissionais" (LELIS, 2001, p.41).

Em outra pesquisa (SILVA, 2005, p.29), encontramos o "habitus professoral", conceito adotado para compreender os diferentes âmbitos de formação docente: a academia como espaço da teoria e a sala de aula escolar como espaço da prática. Ela afirma que "[...] a prática aprende-se quando se está exercendo a profissão e somente com o exercício prático é que é desenvolvido um tipo de habitus" (SILVA, 2005, p.160) - no caso dos professores, o habitus professoral. Por fim, Silva (2005, p.161) define esse habitus como um "[...] modo de ser e de agir de professores e professoras".

Ela afirma que durante o curso de formação, os alunos, futuros professores, praticam um habitus de estudante e não um habitus de professor. A autora parte do princípio de que a prática do aluno é diferente da prática do professor, e que o futuro professor estando na condição de aluno na academia, por ocasião de uma formação teórica, não estrutura um habitus professoral, mas um habitus estudantil, ainda que esteja em processo de formação para atuar como docente. Por meio do conceito de habitus, Silva (2011, p.350) defende a tese de que "[...] os saberes práticos da docência só podem ser aprendidos quando do seu exercício". Nessa interpretação, a dificuldade apresentada pelos professores em início de carreira, segundo Silva (2011, p.354), é "perfeitamente compreensível".

Sobrinho (2011) apresenta os resultados de pesquisas realizadas em algumas cidades do nordeste do Brasil sobre a construção da identidade profissional do professor (a) do ensino básico da rede pública. À luz da teoria praxiológica de Bourdieu, principalmente com os conceitos de habitus e campo, seu objetivo é "pôr em evidência alguns aspectos macro e microssociais da construção do ser professor/professora" (SOBRINHO, 2011, p.190). O autor destaca que as trajetórias desses agentes - seus condicionantes sociais, as estratégias de conservação ou subversão adotadas para inserir-se no campo e as posições ocupadas nesse espaço 
educacional - constituíram um habitus e consequentemente uma identidade profissional.

O pesquisador levanta a hipótese de que as estruturas dessa identidade profissional construída sobre um habitus específico pode se configurar como um aspecto que dificulta a incorporação do novo na prática docente: “[...] podem funcionar como obstáculos simbólicos à incorporação das novidades propostas pelos processos formativos" (SOBRINHO, 2011, p.192). Para Sobrinho (2011, p.195), ser professor é compartilhar "uma cultura específica (um habitus)", cujo processo, longo, de construção inicia-se numa fase anterior à entrada no campo educacional, ou seja, está diretamente relacionado às origens sociais e às trajetórias de vida. Os valores, as crenças, a maneira de agir, de ver e de se ver no espaço educacional são manifestações "que estão na gênese do habitus docente" (SOBRINHO, 2011, p.195).

Estudando as distintas representações sociais construídas pelos professores de licenciatura em Filosofia da Universidade Federal do Piauí (UFPI) sobre a formação docente, Queiroz (2011) entende que essa constituição está relacionada ao habitus e à posição ocupada pelos professores formadores, dentro do campo da academia. Identificando como efeito dessas diferenças de representação o engendramento de práticas distintas e, consequentemente, as lutas e tensões no campo.

Essa autora trata a formação de professores como um subcampo dentro do campo acadêmico e este como um microcosmo dentro do campo educacional. Para isso ela utiliza o conceito de campo de Bourdieu: "A estrutura do campo é um estado da relação de força entre os agentes ou as instituições envolvidas na luta ou, se se preferir, da distribuição do capital específico que, acumulado no decorrer das lutas anteriores, orienta as estratégias posteriores"(BOURDIEU, 2003, p.120).

O problema abordado por Queiroz (2011), diz respeito aos interesses, algumas vezes divergentes, entre os que se ocupam da formação específica e os que tratam da formação pedagógica. Para a autora há uma "cisão entre a formação pedagógica e a formação específica do professor" (QUEIROZ, 2011, p.18). Ela remete ao conceito de campo com suas disputas e hierarquizações, para interpretar as relações entre os agentes pertencentes a cada uma dessas duas dimensões: a dimensão pedagógica e a dimensão específica, dentro das quais existem grupos de professores e uma estrutura de posições bem definida. Como resultado dessas posições, hierarquicamente definidas e ocupadas pelos agentes, tem-se um modo de perceber, de compreender e de desenvolver práticas formativas. O objeto de disputa desse campo, de acordo com Queiroz (2011, p.19), é a formação de professores, ou melhor, é "o sentido que atribuem ao seu objeto de trabalho, a formação de professores".

Há outros pesquisadores, como Soares (2011), Albuquerque (2011) e Bairros 
(2011) que discutem a formação de professores por essa perspectiva sociológica utilizando os conceitos da teoria de Bourdieu, principalmente o conceito de habitus. Todos os autores citados fundamentam a discussão sobre a formação de professores com ênfase num habitus constituído durante o processo de formação docente na universidade, ou constituído no exercício da prática como professor ou ainda, num habitus que se constitui anteriormente a esses processos.

As referências ao conceito de campo - tal como elaborado por Bourdieu -, e suas relações de distinção e poder, são pouco expressivas, ou pouco percebidas. Alguns desses autores falam de campo educacional brasileiro, campo do conhecimento, campo prático, campo do currículo, etc., em um sentido que parece referir-se a uma área de atuação profissional ou área do conhecimento, como expressa Silva (2011, p.338): "cada profissão se efetiva dentro de determinado campo do conhecimento".

Pesquisadores como Lelis (2001) e Sobrinho (2011) avançam um pouco nesse sentido quando expõem determinados elementos característicos do campo: posições, hierarquias, disputas, bens específicos etc., o primeiro ao mencionar a "[...] problemática da profissão vista como campo [...]" com sua hierarquia e suas disputas entre os "professores enquanto sujeitos que ocupam posições distintas [...]" (LELIS, 2001, p.45). O segundo trata o campo nos seus códigos, linguagens e regularidades. Para ele o contato com o campo educacional proporciona "entender e familiarizar-se com os códigos, bens materiais e simbólicos e jogos específicos desse campo" (SOBRINHO, 2011 p.198).

Aplicação dos conceitos de habitus, campo e capital em algumas pesquisas educacionais sobre a formação do professor de Matemática

No âmbito da área disciplinar da Matemática, encontramos algumas pesquisas que articulam os conceitos de Bourdieu com o estudo a respeito da formação do professor dessa área.

Em seu estudo sobre a questão, Rolkousky (2008) busca compreender como um professor de Matemática se constituiu como professor de Matemática, ou seja, como se dá esse percurso, essa trajetória de formação. Para essa investigação, a metodologia de que se vale é a entrevista com os professores, cujas análises fundamentam-se numa perspectiva sociológica baseada em trabalhos de Nobert Elias e Pierre Bourdieu, e também numa perspectiva psicológica utilizando as pesquisas do psicólogo estadunidense Jerome Brunet. 
Para esse pesquisador, o tornar-se professor não está relacionado apenas com a formação na academia, mas se dá ao longo da vida, nas relações: familiares, amistosas e profissionais. Segundo o autor, "não só os cursos de especialização, e capacitação são protagonistas na formação do professor de Matemática" (ROLKOUSKY, 2008, p.65), as experiências vividas em outros espaços também concorrem para essa formação, para esse tornar-se professor.

No que concerne à sociologia como referencial analítico, o autor utiliza o conceito de habitus de Bourdieu para interpretar as falas dos professores e embasar a sua hipótese de que o tornar-se professor inicia-se num período anterior ao exercício da docência e, até mesmo, anterior à formação adquirida na academia. Esse processo de tornar-se professor começa já na infância, no seio familiar onde lhe é inculcado um habitus primário cujas características, disposições, vão constituindo esse professor de Matemática e se revelam na sua prática docente.

Por sua vez, Nolan (2012) aborda a formação de professores de Matemática colocando a formação inicial na academia e a formação adquirida na experiência de sala de aula em dois campos distintos. Discute, também, como os futuros professores procuram relacionar os saberes adquiridos em ambos os espaços para constituir sua prática. Nolan (2012) destaca a rede de relações e práticas discursivas que sustentam a (re)produção de procedimentos tradicionais no ensino da Matemática. Para explicar esse nexo e esse descompasso entre o discurso da universidade e o discurso da escola, e como os professores em início de carreira constroem um discurso na sua prática, a autora recorreu a dois conceitos da teoria de Bourdieu: habitus e campo.

A transição de aluno para professor, no campo da experiência, segundo a autora, ocorre de maneira mais suave, devido ao habitus tradicional formado nesse campo por meio da vivência como aluno, desde a infãncia: pela maneira como foram ensinados e pela observância da prática de outros professores. Para esses futuros professores, segundo Nolan (2012), é mais difícil empregar métodos alternativos, pois, o habitus formado na experiência como aluno está fortemente enraizado, e isso dificulta uma prática docente mais compatível com a formação acadêmica apontada pela autora.

Utilizando o conceito de campo para analisar um curso de formação de professores de Matemática, Alvermann et al. (2001) observa que o professor formador, de posse de determinado tipo de capital, tende a reforçar e valorizar esse capital dentro do campo. Por sua vez, o aluno percebe tanto as regras do jogo desse campo, reconhecendo o capital cultural - que é valorizado e com ele as relações de poder -, quanto os agentes que estão em melhores posições na hierarquia desse espaço. O aluno tende, portanto, segundo o autor, a reagir de acordo com essa 
percepção.

\section{Aplicação do conceito de campo na Educação Matemática}

Apesar de alguns dos pesquisadores apresentados fazerem menção ao conceito de campo, destacamos aqui as pesquisas de Vilela (2007), Carrião (2008), Passos (2017) e Farias (2017), por tornarem mais explícito, em suas pesquisas, esse conceito e seus elementos característicos.

Com base no conceito sociológico de campo de Pierre Bourdieu, Vilela (2007), ao investigar as adjetivações da expressão matemática - matemática acadêmica, matemática escolar, matemática pura, matemática aplicada, matemática formal, matemática informal etc. e as práticas a elas relacionadas - interpreta o espaço social das práticas matemáticas como um espaço de luta, como um campo.

Dando destaque à matemática acadêmica e à matemática escolar, a autora interpreta esses pares de adjetivações como a manifestação de uma tensão entre dois polos do campo da matemática: o polo da matemática acadêmica e o polo da matemática escolar: "neste sentido, interpretamos as adjetivações como tensão no campo das matemáticas" (VILELA, 2007, p.215). Essa tensão, segundo Vilela (2007), manifesta outra: a tensão que existe entre matemáticos e educadores, dominantes e dominados, agentes que possuem interesses, algumas vezes, muito divergentes, no campo, no que tange à formação de professores e ao currículo escolar:

Há uma disputa evidente pela atuação profissional na formação dos professores de matemática [...]. Além da atuação profissional, também está em disputa a autoridade para determinação dos programas de ensino em que está em questão a própria função da escola, que tem sido objeto de reflexão e investigação exclusivamente dos educadores já que os matemáticos parecem permanecer presos a proposta positivista de sua função de transmitir os conteúdos científicos (VILELA, 2007, p.222).

Carrião (2008) analisa os discursos produzidos nas salas de aula de Matemática numa perspectiva sociológica, dentro da teoria de Bourdieu, dos condicionantes desse discurso. Vale-se do conceito de campo para explicar os vínculos entre os envolvidos na dinâmica discursiva da sala de aula: "A sala de aula pode ser definida como campo, nos termos de Bourdieu, pois ela é um espaço estruturado, com suas próprias leis de funcionamento e suas próprias relações de força, 
refletindo apenas indiretamente os elementos externos". (CARRIÃO, 2008, p.124).

Nesse sentido, ele fala sobre aspectos que condicionam o discurso (que pode ser expresso, também, pelo silêncio) nesse espaço: a influência do discurso da Matemática acadêmica, "no caso da aula de Matemática, são os gêneros mais explicitamente ligados ao campo da matemática acadêmica que são mais valorizados" (CARRIÃO, 2008, p.40); as relações entre professor e aluno e entre alunos, o que ele vai definir como "as posições sociais na sala de aula" (CARRIÃO, 2008, p.18).

Segundo o autor, o professor detém uma posição social privilegiada na sala de aula, em relação aos alunos, assim como os alunos que apresentam melhor desempenho ou que vieram de escolas bem conceituadas estão em melhor posição do que seus colegas, "no campo da sala de aula, por exemplo, a nota do aluno terá mais influência na sua posição social do que seu capital econômico, [...]” (CARRIÃO, 2008, p39). É nesse cenário da sala de aula, interpretado como campo, que Carrião (2008) vai defender as disputas pelas posições e pelo direito de ser ouvido e acreditado, pelo direito de participar das interações discursivas e de ter seu discurso legitimado, principalmente dentro do espaço da sala de aula.

Enquanto Vilela (2007, p.229) teve como inspiração inicial do seu estudo a etnomatemática, ou segundo a autora: "a possibilidade de constituir uma base filosófica para a etnomatemática", Passos (2017), motivada por essa inspiração e sob uma orientação sociológica, estuda os aspectos que deram condições para a produção e legitimação da etnomatemática enquanto uma área que vale a pena ser pesquisada.

Para realizar suas análises, Passos (2017) apoia-se principalmente no conceito de campo de Bourdieu. Apesar de não ter como objeto de pesquisa a formação de professores, a autora defende a estreita relação entre a compreensão das lutas para legitimar a etnomatemática e a formação docente numa perspectiva que valoriza as diferentes práticas matemáticas: "relações entre etnomatemática e o ensino de matemática são observadas na análise que encaminhamos em torno das condições de produção e legitimação desta área de pesquisa" (PASSOS, 2017, p.69).

\section{Um desenho do campo da Matemática}

Em nossa pesquisa de doutorado (FARIAS, 2017), tomamos como base a compreensão, exposta por Vilela (2007), da Matemática como um campo no qual ela considera como polos de disputa a Matemática acadêmica, praticada por matemáticos, e a matemática escolar, praticada por professores. Motivados por essa maneira de ver a matemática, não só lidamos com os conceitos de Pierre Bourdieu, mas propomos 
também um desenho do campo da Matemática.

Um dos nossos objetivos é, mapeando esse campo, compreender ou interpretar as relações estabelecidas entre os matemáticos que pertencem ao Instituto de Matemática Pura e Aplicada (IMPA), Instituição reconhecida nacional e internacionalmente pelas pesquisas desenvolvidas nas áreas de matemática pura e aplicada.

Procuramos analisar, especificamente, as relações entre os matemáticos que se dedicam à pesquisa e os matemáticos que participam de atividades atinentes ao ensino, notadamente os que atuam em um programa de formação de professores em nível de mestrado, o Programa de Mestrado Profissional em Matemática em Rede Nacional (Profmat), na condição de gestores, ou seja, membros do conselho acadêmicoadministrativo. Para melhor compreensão, ao longo desse artigo, denominamos esse grupo de pesquisadores de Pesquisadores Profmat Impa.

Para proceder com o desenho do campo da matemática apoiamo-nos sobre a noção de campo de Bourdieu quando afirma que existem aspectos que são comuns a todos os campos, isto é, existem elementos fundantes e invariantes que definem um espaço social como campo:

Há leis gerais dos campos: campos tão diferentes como o campo da política, o campo da filosofia, o campo da religião têm leis de funcionamento invariantes (é isso que faz com que o projeto de uma teoria geral não seja insensato e com que, desde já, posamos servir-nos do que aprendemos sobre o funcionamento de cada campo particular para interrogarmos e interpretarmos outros campos, superando assim a antinomia mortal da monografia ideográfica e da teoria formal e vazia) (BOURDIEU, 2003, p.119).

Fundamentado nessa teoria sociológica construímos o campo da matemática com seus elementos característicos relativamente invariantes, conforme explicitados na sequência:

\section{Capitais específicos}

Em todo campo existem os capitais específicos que têm seu valor nos limites do campo, também ele, específico. Bourdieu (2013a, p.118) afirma que "no interior de cada um dos campos há uma hierarquia social dos objetos [...]" e que:

Construir o espaço social é construir uma distribuição, sobre um 
plano (fictício) de duas dimensões, do conjunto das posições pertinentes na estrutura de um mundo social, e do conjunto das propriedades e das práticas estruturalmente ligadas a essas posições. Os agentes singulares são distribuídos por esse espaço em virtude de sua posição nas distribuições das duas espécies maiores de capital, o capital econômico e o capital cultural, sendo o afastamento de dois agentes nessas distribuições uma medida de sua distância social (BOURDIEU, 2000, p.40).

Adotamos duas espécies principais do capital específico: o capital científico e o político-social. Para o capital científico definimos os seguintes objetos: a publicação de livros e artigos; os prêmios e títulos recebidos; a formação acadêmica inicial, ou seja, os cursos de graduação - engenharia, medicina, matemática, licenciatura etc. -; a formação em nível de pós-graduação - mestrado, doutorado, pós-doutorado -; e a atuação profissional em instituições reconhecidas nacional e internacionalmente. Para o capital-político social utilizamos: a participação em conselhos, diretorias, coordenadorias e secretarias em reconhecidas instituições; a atuação profissional no exterior; a participação em bancas de teses e dissertações; o reconhecimento materializado por meio de prêmios concedidos pelas renomadas instituições brasileiras e estrangeiras; e as parcerias em trabalhos acadêmicos. A posição ocupada pelos agentes, no campo, está diretamente relacionada com a posse desses capitais, ou seja, com a quantidade e a qualidade dos capitais possuídos.

\section{Espaço estruturado de posições}

A posição ocupada no campo vai depender do volume de capital global específico possuído por cada agente, "a estrutura de distribuição do capital determina a estrutura do campo, ou seja, as relações de força entre os agentes [...]" (BOURDIEU, 2013d, p.53).

As relações de forças ocorrem entre os agentes e as instituições que fazem parte desse espaço social. As posições estão diretamente relacionadas com a hierarquização, tanto dos agentes quanto das instituições que fazem parte do campo. Nesse sentido utilizamos como ponto de partida para a hierarquização das instituições e, consequentemente, a posição por elas ocupada no campo, o reconhecimento no cenário nacional e internacional.

O Instituto de Matemática Pura e Aplicada (IMPA) é considerado como a mais importante instituição brasileira no campo da matemática e, por conseguinte, os agentes que dele fazem parte são considerados distintos, no sentido de uma posição 
relevante, no campo: "pensamos ser razoável adotar os pesquisadores do Impa como expoentes no campo da matemática no Brasil" (FARIAS, 2017, p.144). Essa conclusão baseia-se nas análises dos documentos: Relatórios de Atividades do Impa, Relatórios de Gestão do Impa, notícias de jornais e artigos científicos em que pesquisadores relatam a importância desse Instituto: "pertencer ao quadro de pesquisadores desse instituto é quase uma garantia de se alcançar entre a comunidade de matemáticos do país um lugar de destaque" (SILVA, 2009, p.915).

Os parâmetros adotados para posicionar o Impa, nesse desenho do campo, foram as produções científicas publicadas em revistas de alto nível. Fizemos um comparativo com outras instituições internacionais como: Harvard, Berkeley, Princeton, entre outras, a partir do comparativo apresentado nos relatórios do Impa que relacionam o número de pesquisadores de cada instituição e o número de produções científicas. Nesse comparativo o Instituto ocupa uma posição de destaque em relação as instituições mencionadas. Para classificar as demais instituições acadêmicas, como as universidades brasileiras e as estrangeiras, com as quais os pesquisadores analisados têm alguma vinculação, consideramos a posição ocupada no ranking mundial e brasileiro de acordo com alguns órgãos nacionais e internacionais como: Academic Ranking of World Universities e QS University Rankings BRICS.

Ao definir as instituições e os pesquisadores do Impa como os agentes desse campo e, além disso, ao estabelecer uma estrutura hierárquica a partir dos capitais considerados, esboçamos um desenho do campo. O passo seguinte foi posicionar tais agentes de acordo com o volume dos capitais específicos. Para isso adotamos como documentos de pesquisa o currículo Lattes dos pesquisadores e outros documentos como: portarias, relatórios etc., encontrados nos websites das instituições: IMPA e da Sociedade Brasileira de Matemática (SBM).

\section{Dominantes e dominados}

De acordo com o volume de capital possuído, os agentes podem ser posicionados no campo, no polo dominante ou no polo dominado:

Em todo campo se colocam - com forças mais ou menos desiguais segundo a estrutura de distribuição do capital no campo - os dominantes, em posições mais altas na estrutura de distribuição de capital científico, e os dominados, os novatos, que possuem um capital científico tanto mais importante quanto maior a importância dos recursos científicos acumulados no campo (BOURDIEU, 
2013a, p.126).

Construímos o desenho do campo posicionando os agentes, os matemáticos, em cada um dos polos: o polo dominante ou o dominado. A posição ocupada pelos matemáticos está relacionada com a posse dos capitais considerados nessa pesquisa: o científico e o político social, ou seja, os agentes foram posicionados de acordo com o volume global dos dois tipos de capitais possuídos. Posicionamos as instituições que fazem parte desse campo, de acordo com o reconhecimento no cenário acadêmico nacional e internacional. Aos poucos vamos constituindo o mapa, o desenho, do campo da Matemática.

Inicialmente os agentes são posicionados hierarquicamente de acordo com a quantidade de cada espécie de capital que eles possuem, ou seja, para cada espécie de capital, seja ele de natureza científica seja político-social, construímos uma tabela na qual os matemáticos são ordenados de acordo com esse princípio. Aqueles que possuem uma quantidade maior daquela espécie de capital são definidos como os dominantes; ao contrário, os que detêm as menores quantidades são definidos como os dominados. Tomando como exemplo a quantidade de artigos publicados em periódicos, posicionamos o pesquisador Alfredo Noel Iusem no polo dominante do campo da Matemática pelo fato desse pesquisador ter publicado 119 artigos, enquanto o pesquisador Elon Lages Lima, com apenas 13 publicações, ocupa uma posição no polo dominado.

Adotando esse mesmo critério para todas as demais espécies de capital, identificamos um grupo de pesquisadores que se repetem nas posições de maior volume de cada capital. Esse grupo denominamos de Pesquisadores de Elite (FARIAS, 2017, p.183). Interpretamos a relação entre os Pesquisadores de Elite e os Pesquisadores Profmat Impa - grupo de matemáticos que atuam no Profmat - como uma relação entre os dominantes, posição que atribuímos aos Pesquisadores de Elite, e os dominados, posição atribuída aos Pesquisadores Profmat Impa. Uma relação, portanto, caracterizada por uma disputa pela definição do que é Matemática, do que é ser professor de Matemática e de como ensiná-la. Uma luta entre agentes que pertencem ao mesmo campo e produzem os mesmos produtos.

\section{Luta concorrencial}

Todo campo caracteriza-se por ser o lugar de uma luta, lugar de disputa entre dominantes e dominados, entre os agentes ocupantes das posições privilegiadas, que são as posições de autoridade dentro do campo, e os pretendentes que desejam ocupar 
essas posições e ter esses privilégios: “[...] é o lugar e o espaço de uma luta concorrencial. O que está em luta são os monopólios da autoridade científica e da competência científica (capacidade de falar e agir legitimamente)". (BOURDIEU, 2013a, p.112).

Uma disputa entre pares, entre os matemáticos. Agentes concorrentes que são ao mesmo tempo produtores e consumidores. No campo, os concorrentes são os principais consumidores. É para eles que se produz e é deles que se espera a aprovação dos produtos: aprovação de um artigo, de um projeto de pesquisa, aprovação de uma dissertação ou tese, uma carta de recomendação, a coautoria de um artigo etc. Algumas vezes ocorrem aprovações e reprovações camufladas, principalmente quando envolve capital político-social, como a participação em ciclos de amizade, o reconhecimento por parte da academia, o convite, ou não, para participar de uma banca etc.

O campo é esse espaço relativamente autônomo, com suas próprias leis de funcionamento, sua dinâmica, seus capitais específicos, seus agentes posicionados e suas lutas. Para alcançar êxito nessas disputas é necessário ter as armas específicas e dominar a lógica, a regra desse jogo, também ele específico: "Se você deseja triunfar sobre um matemático, é preciso fazê-lo matematicamente pela demonstração ou refutação. Evidentemente, há sempre a possibilidade de que o soldado romano corte a cabeça de um matemático, mas isso é um "erro de categoria' diriam os filósofos". (BOURDIEU, 2004b, p.32).

Nessa disputa, os matemáticos mobilizam seus trunfos: os capitais, o nome de família, o nome da instituição, etc. Uma disputa que envolve os agentes e as instituições. Uma luta entre agentes posicionados em polos opostos: de um lado há um grupo cuja prática matemática está relacionada à Matemática acadêmica, seja pura ou aplicada e, de outro lado, um grupo que tem sua prática matemática relacionada ao ensino. Uma disputa que em sua base estão as diferentes maneiras de ver e de lidar com a matemática.

Quando nos referimos a Matemática acadêmica estamos tratando de uma matemática que, segundo Moreira, Cury e Vianna (2005, p.39), é objeto de estudo dos matemáticos. Estamos falando de uma prática específica de um grupo de profissionais, os matemáticos, e tudo que isso implica: a maneira de lidar com a matemática, o local dessa prática, os objetivos, os destinatários ou beneficiários da pesquisa etc. Isso difere da prática matemática voltada para o ensino que contempla objetivos diferentes, destina-se a um público diferente, desenvolve-se em locais diferentes etc.

No entanto, apesar das diferenças entre essas duas práticas, interpretamos a relação entre os Pesquisadores Profmat Impa e os Pesquisadores de Elite dentro desse 
contexto de uma luta concorrencial: os matemáticos pesquisadores em matemática e os matemáticos que trabalham numa perspectiva do ensino de matemática, ou seja, entre a Matemática acadêmica e a matemática do ensino, esta última buscando reconhecimento e legitimidade na Matemática acadêmica; seus praticantes buscando autorização, no sentido de autoridade, daqueles que, por serem dominantes, podem autorizar, legitimar e reconhecer uma prática como sendo uma prática matemática.

\section{Objeto de disputa}

A luta concorrencial, essa disputa entre agentes - que são ao mesmo tempo concorrentes e consumidores -, dá-se em torno de um objeto:

Está sempre em jogo o poder de impor uma definição de ciência [...], mas de acordo com seus interesses específicos. A definição mais apropriada será aquela que lhe permita ocupar legitimamente a posição dominante e a que assegure aos talentos científicos de que ele é detentor (BOURDIEU, 2013a, p. 117).

Nesse espaço, que chamamos de campo da matemática, está em jogo a definição do que é matemática e, portanto, de um modelo: de ensino, de professor, de currículo, de aluno, de escola. Para Farias (2017) são os matemáticos, como dominantes do campo, que impõem esse modelo, que impõem essa definição, por meio, dentre outras ações, de um programa de formação de professores com polos de aulas presenciais em todos os estados brasileiros - o Profmat. Esse Programa foi idealizado e implantado por matemáticos e apoiado por instituições como o IMPA e a SBM que, mesmo não tendo experiência reconhecida na área de pesquisa em formação de professores, implanta um programa em nível nacional, com apoio do Governo Federal e de várias universidades. Aliás, um programa que serviu de modelo para outros programas de mesma natureza em outras áreas do conhecimento, como o mestrado profissional em letras e o mestrado profissional em Física. Para Bourdieu, "[...] é dominante quem consegue impor uma definição da ciência pela qual a realização mais perfeita consiste em ter, ser e fazer aquilo que eles têm, são e fazem" (BOURDIEU, 2013a, p.118).

Por essa análise, observando outra relação que ocorre no campo, entre matemáticos e educadores, podemos inferir que os matemáticos são, portanto, em relação aos educadores, dominantes no campo da Matemática, pois conseguem impor um modelo de formação de professores fundamentado apenas no aprofundamento do 
conteúdo específico, enquanto vários pesquisadores, como Moreira et. al. (2012, p.12), defendem que a preparação do professor "precisa mobilizar, em tese, diferentes tipos de conhecimentos [...] em diferentes campos do saber".

No entanto, como "o real é relacional" (BOURDIEU, 2011, p.16), dentro do grupo dos dominantes, pesquisadores pertencentes ao IMPA, há um grupo dominado, como já havíamos comentado, que é o grupo de Pesquisadores Profmat Impa.

Ao tratar da atuação dos dominantes no campo religioso, Bourdieu (2004a, p.120) afirma que "o campo religioso é um espaço no qual agentes que é preciso definir (padre, profeta, feiticeiro etc.) lutam pela imposição da definição legítima não só do religioso, mas também das diferentes maneiras de desempenhar o papel religioso".

Parafraseando Bourdieu, no espaço restrito dos pesquisadores do IMPA, ou seja, entre os matemáticos, também existem os dominantes que, impõem não apenas a definição do que é Matemática, mas impõem a forma de como lidar com a Matemática e de como ser um matemático.

Dentro do que Farias (2017) classificou como grupos polarizados do campo Pesquisadores de Elite e Pesquisadores Profmat Impa -, são os Pesquisadores de Elite que impõem esse modo de ver, de fazer e de apreciar a Matemática. Nesse sentido, cada agente atua dentro do campo de acordo com a sua posição, de acordo com os seus capitais e interesses.

\section{Estratégias e interesses}

A prática dos agentes está condicionada às posições que eles ocupam dentro do campo: os dominantes, regularmente, buscam conservar a ordem que os favorece, já os dominados buscam, na maioria das vezes, subverter essa ordem:

Os que, num estado determinado de relação de força, monopolizam [...] o capital específico, fundamento do poder ou da autoridade específica característica de um campo, inclinam-se para estratégias de conservação - as que, nos campos de produção de bens culturais, tendem para a defesa da ortodoxia -, ao passo que os menos providos de capital [...] inclinam-se para as estratégias de subversão - as da heresia (BOURDIEU, 2003, p.121).

As estratégias dos matemáticos em conformidade com o grupo a que pertencem, direcionam-se para investimentos em produções específicas, como artigos ou livros, e ainda, para cada produção há uma estratégia para escolher a quem se 
destina o produto, "uma estratégia que busca, por parte dos agentes, o reconhecimento, pelos pares, ou a notoriedade, pelo público" (FARIAS, 2017, p.192).

As estratégias dos Pesquisadores de Elite em investir nos capitais mais valorizados, como: na produção de artigos; em artigos escritos em língua estrangeira; nas orientações de pós-graduação em nível de mestrado e doutorado; na formação e atuação profissional no exterior; na formação e atuação profissional, se no Brasil, nas melhores universidades - aquelas posicionadas entre as dez melhores do país; nos prêmios e títulos nacionais e internacionais; e no reconhecimento, por meio dos prêmios e títulos, por instituições consagradas no Brasil. Enquanto os pesquisadores envolvidos com o Profmat investem: na produção de artigos escritos em língua portuguesa; na produção de livros escritos em português ou em língua estrangeira em sua maioria destinados aos professores do ensino básico ou alunos de graduação -; na ocupação de cargos e funções em reconhecidas instituições brasileiras; e nos prêmios e títulos nacionais e internacionais.

A trajetória de investimento dos dois grupos de pesquisadores, [...] mostra-se em oposição uma com a outra. [...] um grupo elege determinados tipos de capitais que merecem ser investidos, já o outro grupo faz uma escolha inversa, ou seja, elege esses mesmos capitais como não merecedores de grandes investimentos. De outro modo, [...] interpretamos esse movimento como a manutenção das distâncias de distinção, em que, enquanto os Pesquisadores Profmat Impa parecem chegar atrasados aos capitais mais valorizados, os Pesquisadores de Elite abandonam determinados capitais pela desvalorização, pela perda de raridade, que ocorre quando se tornam alcançáveis por outros grupos (FARIAS, 2017, p.186).

As estratégias utilizadas na luta pela conservação ou subversão da ordem do campo, atribuídas respectivamente aos dominantes e aos dominados, tomam, de acordo com Lahire (2002, p.48), "a forma de um conflito entre 'antigos' e 'modernos', 'ortodoxos' e 'heterodoxos'”.

\section{Ortodoxia e heresia}

Partindo do pressuposto de que todo campo possui suas leis próprias, sua definição e imposição do que é e do que não é legítimo no campo e, portanto, do que é a verdade estabelecida, afirmamos que existe no campo da Matemática "o discurso 
herético dos educadores" (FARIAS, 2017, p.105) e "o discurso ortodoxo dos matemáticos" (FARIAS, 2017, p.104). Nesse sentido interpretamos, portanto, os matemáticos como os pertencentes à ortodoxia, ou seja, aqueles que definem e defendem a verdade definida por eles. Já os que se ocupam de atividades relacionadas ao ensino, especificamente à formação de professores do Ensino Básico, pertencem ao grupo dos hereges. Os discursos ortodoxos ou heréticos manifestam-se nas práticas: "porque por elas se expõe e se impõe uma visão de mundo" (FARIAS, 2017, p.106).

No âmbito da formação do professor de Matemática, o discurso ortodoxo que define uma prática matemática - a Matemática acadêmica - como universal, única e verdadeira, manifesta-se no Profmat, por meio das avaliações, do material didático, do currículo, da formação dos formadores. Observamos nesse Programa uma valorização do conteúdo específico, em detrimento de outros conhecimentos necessários à prática profissional do professor, como os conhecimentos defendidos pelo discurso herético dos educadores: "a Sociologia, a Didática, a Psicologia e demais conhecimentos não só ligados ao conteúdo específico da disciplina, mas também às ciências cognitivas" (FARIAS, 2017, p.101). "Dessa forma não há apenas a valorização do conteúdo matemático, não há apenas a valorização de um tipo de saber formativo docente, mas há a valorização de um saber e de uma abordagem do conteúdo estritamente ligado à prática de um grupo: o dos matemáticos" (FARIAS, 2017, p.125).

O discurso ortodoxo impõe-se. Mesmo entre os hereges, o discurso ortodoxo é fortemente sentido, porque se manifesta como a verdade do campo - todos os constrangimentos sofridos pelos agentes nesse espaço social têm relação com essa doxa:

Dentro desta análise sociológica a que nos propomos, a prática do professor pode ser desenvolvida num ambiente diferente, com objetivos e resultados distintos, com público diferenciado, mas está sempre referenciada à Matemática acadêmica - à formalidade, ao erro, à demonstração etc. (FARIAS, 2017, p.103).

Esses foram alguns elementos utilizados para desenhar o campo da Matemática. Fundamentados na sociologia de Bourdieu e nas análises de outros campos, ou seja, ao modo de Bourdieu (2003) nos servimos do que se aprende sobre o funcionamento de cada campo particular para não só interrogar e interpretar, mas para construir outros campos, nesse caso, construir o campo da matemática.

Nesse trabalho não queríamos somente propor um desenho do campo da Matemática, mas convidar o leitor a, junto conosco, construir esse campo: 
estabelecendo os capitais específicos; definindo os agentes e as instituições envolvidas; posicionando esses agentes e essas instituições, de acordo com o volume dos capitais específicos; constituindo o objeto de disputa e as lutas peculiares em torno desse objeto; definindo as posições de dominantes e dominados bem como as estratégias para manter-se ou para alcançar as melhores posições na estrutura hierárquica do campo; definindo a doxa do campo, isto é, a crença pela qual os agentes se manifestam como ortodoxos ou heterodoxos.

Ao desenhar o campo da Matemática, nossa intenção foi a de propor uma interpretação sociológica, um ponto de vista das práticas dos agentes envolvidos e atuantes nesse espaço social. Práticas que se orientam por interesses; escolhas que estão na base das estratégias; ações condicionadas socialmente pela posição ocupada nesse espaço social e pela disposição, ou seja, pelo habitus.

\section{Considerações finais}

Por fim, resta-nos a convicção de que, ao utilizar a teoria sociológica de Pierre Bourdieu para analisar determinado fenômeno social, não nos posicionamos como juízes, porque não somo imparciais e neutros - mesmo entendendo ser de fundamental importância a busca pelo rigor científico, pela imparcialidade e pela neutralidade na atividade de pesquisa -, mas, ao contrário, aqui, contestando essa impessoalidade, pensamos em evidenciar os constrangimentos do espaço social ao qual pertencemos: "[...] a atividade científica é uma atividade social e a construção científica é também uma construção social da realidade [...]" (BOURDIEU, 2011, p.87).

A utilização dos conceitos de Bourdieu não nos autoriza a fazer julgamentos de valor, nem a nos colocarmos como detentores da verdade, tampouco a agir como profetas, como conhecedores do bem e do mal. Ao contrário, a nossa postura diante do nosso objeto de pesquisa, ao adotar os pressupostos metodológicos dessa teoria, convida-nos a realizar, ou melhor, a aplicar em nós mesmos uma sócio análise para compreendermos que também nós fazemos parte desse espaço, somos agentes dentro do campo e, portanto, sujeitos que estamos aos constrangimentos, nossas escolhas são condicionadas e interessadas. Temos assim como todos os agentes nossas estratégias, que não são resultado de um cálculo racional, nem tampouco movidas inconscientemente pelas estruturas objetivas.

Olhar para a disciplina Matemática como um campo, nessa perspectiva sociológica, é fazer uma interpretação, dentre as várias possíveis, sobre as relações estabelecidas, dentro desse espaço, entre matemáticos, entre matemáticos e 
educadores, entre a pesquisa e o ensino, entre o bacharelado e a licenciatura, entre a universidade e a escola, entre as instituições de ensino superior, entre homens e mulheres etc. Essa interpretação oferece-nos a possibilidade de poder olhar para a formação do professor de Matemática como uma estratégia de imposição de uma maneira de ver a matemática, de se ver a partir dessa matemática e de ver os outros com esse modelo de referência. Ou seja, pensar a Matemática como um campo é pensar como essas relações implicam modos de classificação: maneiras de classificar e de se classificar, e da mesma forma também de desclassificar a si mesmo e os outros.

Uma abordagem metodológica que considera as trajetórias de cada agente e as relações entre eles dentro de um tempo e de um espaço histórico. Uma metodologia que, se por um lado, nos autoriza a lançar mão de uma multiplicidade de procedimentos e técnicas, para apreender o objeto, por outro lado, faz exigências, solicita respostas, rejeita o objeto dado como pronto e acabado e reivindica a construção desse objeto. O trabalho de pesquisa com a noção de campo é, “[...] um modo de construção do objeto que vai comandar todas as opções práticas da pesquisa. Ela funciona como um sinal que lembra o que há que fazer [...]" (BOURDIEU, 1989, p.27).

Além disso, cada ação, cada escolha e cada posição só podem ser analisadas levando-se em conta as relações com outras ações, com outras escolhas e com outras posições: "o real é relacional" (BOURDIEU, 2011, p.16). Ser dominante ou dominado está diretamente ligado com as relações entres as posições consideradas no campo, os dominantes são dominantes numa determinada relação, os dominados são dominados num campo e numa relação particular. Em outros campos ou em outras relações dentro do mesmo campo essas posições podem variar.

Ser dominante não pode ser entendido como ser o malvado, o vilão, aquele que tudo pode, e ser dominado ser o bondoso, ser o mocinho, ser aquele que nada pode. Dominantes e dominados estão sob os mesmos constrangimentos do campo, sob as mesmas leis e exigências. Dominantes e dominados têm um trabalho a fazer, cada um deles age de acordo com a sua posição e disposição. No entanto, ambos têm interesse na manutenção do campo, suas ações são pautadas, por vezes, na cumplicidade: "O desacordo supõe um acordo nos terrenos de desacordo, e os conflitos manifestados entre as tendências e as doutrinas dissimulam, aos olhos dos que deles participam, a cumplicidade em que implicam e que choca o observador estranho ao sistema". (BOURDIEU, 2013c, p.207).

Esses conceitos, principalmente o de campo aqui discutido, mostraram-se potentes, pois nos oferecem um ponto de vista sociológico da Matemática, enquanto um espaço social de produção, de consagração dos produtores, de legitimação das 
verdades estabelecidas e de disputas entre os concorrentes pelo monopólio dessa legitimação.

Ao analisar a formação do professor de matemática, dentro dessa perspectiva sociológica que nos possibilitou olhar para a Matemática como um campo, conseguimos oferecer outras interpretações e um ponto de vista que pode contribuir com o debate acerca da formação docente no âmbito da Matemática. Por esses resultados, acreditamos que essa abordagem teórico-metodológica, fundamentada na teoria de Bourdieu, principalmente no conceito de campo, constitui-se como um instrumento que pode dar grandes contribuições para uma compreensão e um aprofundamento das questões que dizem respeito não somente a formação de professores de Matemática, mas a outros aspectos relacionados a essa área disciplinar.

\section{DRAWING THE FIELD OF MATHEMATICS: APPLICATION OF THE CONCEPTS OF PIERRE BOURDIEU IN MATHEMATICAL EDUCATION}

ABSTRACT: From Pierre Bourdieu's sociological theory and the research in Mathematical Education, it is presented in this article an interpretation of mathematics as a field: with its laws, agents, capitals, disputes, tastes and distinctions. Our goal was to design the field of mathematics, from the analysis of a professional mathematics Master's Program in national network (Profmat). This program was conceived and implemented by the Sociedade Brasileira de Matemática ( Brazilian Mathematics Society) and by Instituto de Matemática Pura e Aplicada( Institute of Pure and Applied Mathematics), institutions recognized as developing high-level research in mathematics, but not recognized in the context of research in teacher training. The sociological investigation carried out by elaborating the notion of field, allowed an understanding of Profmat as a strategy for valuing a mathematical practice and an understanding of mathematics as a hierarchical space of agents in dispute for the right to define what is mathematics and who has enough distinction to define it.

KEYWORDS: Field of Mathematics. Education. Academic mathematics. Teacher Training.

\section{DeLINEANDO EL CAMPO DE LA MATEMÁTICA: APLICACIÓN DE LOS CONCEPTOS DE PIERRE BOURDIEU EN LA EDUCACIÓN}




\section{MATEMÁTICA}

RESUMEN: A partir de la teoría sociológica de Pierre Bourdieu y de las investigaciones en Educación Matemática presentamos, en este trabajo, una interpretación de la Matemática como campo: con sus leyes, agentes, capitales, disputas, gustos y distinciones. Nuestro objetivo fue delinear el campo de la matemática, partiendo del análisis de un Programa de maestría profesional en matemática en red nacional (Profmat). Este programa fue realizado e implantado por la Sociedad Brasilera de Matemática y por el Instituto de Matemática Pura y Aplicada, instituciones que, reconocidas por desarrollar investigación de alto nivel en matemática, no son reconocidas en el ámbito de las investigaciones en formación de profesores. La investigación sociológica, realizada mediante la elaboración de la noción de campo, permitió una comprensión del Profmat como una estrategia de valoración de una práctica Matemática y una comprensión de la Matemática en cuanto a un espacio jerarquizado de agentes en disputa por el derecho de definir lo que es matemática y quien tiene distinción suficiente para definirla.

PALABRAS CLAVE: Campo de la Matemática. Educación. Matemática académica. Formación de Profesores.

\section{Referências}

ALBUQUERQUE, Lia Matos Brito de. Habitus, representações sociais e a construção identitária dos professores de Maracanaú. 2011. 152p. Dissertação (Mestrado em Educação) - Centro de Ciências Sociais Aplicadas, Universidade Federal do Rio Grande do Norte, Natal, 2011.

ALVERMANN, Donna et al. Content area reading pedagogy and domain knowledge: a Bourdieusian analysis. The Australian Educational Researcher, Austrália, v.38, p.203-220, 2001.

BAIRROS, Mariangela Silveira. Habitus e a atuação docente: Estudo sobre as conexões entre habitus e trabalho docente. 2011. $151 \mathrm{f}$. Tese (Doutorado em Educação) - Faculdade de Educação, Universidade Federal do Rio Grande do Sul, Porto alegre, 2011. 
BOURDIEU, Pierre. O campo científico. Tradução de Paula Montero. In: ORTIZ, Renato. (Org.). A sociologia de Pierre Bourdieu. São Paulo: Olho d’Água, 2013a. p.112-143.

. Esboço de uma teoria da prática. Tradução de Paula Montero. In: ORTIZ, Renato (Org.). A sociologia de Pierre Bourdieu. São Paulo: Olho d‘Água, 2013b.

. A economia das trocas simbólicas. Tradução de Sergio Miceli, Silvia de Almeida Pardo, Sonia Miceli e Wilson Campos Vieira. 7. ed. São Paulo: Perspectiva, 2013c.

. Para uma sociologia da ciência. Tradução de Pedro Elói Duarte. Lisboa: Edições 70, 2013d.

. Razões Práticas: sobre a teoria da ação. Tradução de Mariza Corrêa. 11. ed. Campinas: Papirus, 2011.

. Coisas ditas. Tradução de Cássia R. da Silveira e Denise Moreno Pegorim. São Paulo: Brasiliense, 2004a.

. Os usos sociais da ciência: por uma sociologia clínica do campo científico. Tradução de Denice Bárbara Catani. São Paulo: Unesp, 2004b.

. Questões de sociologia. Tradução de Miguel Serras Pereira. Lisboa: Fim de século, 2003.

. O campo econômico: a dimensão simbólica da dominação. Tradução Roberto Leal Ferreira. Campinas: Papirus, 2000.

. O poder simbólico. Tradução de Fernando Tomaz. Rio de Janeiro: Editora Bertrand Brasil, 1989.

BOURDIEU, Pierre; PASSERON, Jean-Claude. A Reprodução. Rio de Janeiro: Francisco Alves, 1975.

CARRIÃO, Airton Machado. Marcas do discurso da Matemática escolar: uma investigação sobre as interações discursivas nas aulas do Ensino Médio. 2008. 226 p. 
Tese (Doutorado em Educação) - Universidade Federal de Minas Gerais, Belo Horizonte, 2008.

CATANI, Denice Bárbara. Pierre Bourdieu e a História (da Educação). In. FARIA FILHO, Luciano Mendes de (Org.). Pensadores sociais e história da educação. 3. ed. Belo Horizonte: Autêntica, 2011.

CATANI, Afrânio Mendes; CATANI, Denice Bárbara; PEREIRA, Gilson, R de M. As apropriações das obras de Pierre Bourdieu no campo educacional brasileiro através de periódicos da área. Revista Brasileira de Educação, Rio de Janeiro, n. 17, p.63$85,2001$.

FARIAS, José Vilani. O Profmat e as relações distintivas no campo da Matemática. 2017. 295f. Tese (Doutorado em educação) - Centro de Educação e Ciências Humanas, Universidade Federal de São Carlos, São Carlos, 2017.

GONÇALVES, Nadia G; GONÇALVES, Sandro A. Pierre Bourdieu: Educação para além da reprodução. 2. ed. Petrópolis, RJ: Vozes, 2011.

LAHIRE, Bernard. Reprodução ou prolongamentos críticos? Educação \& Sociedade, Campinas, v.23, no 78, p.37-55, 2002.

LELIS, Isabel. Profissão docente: uma rede de histórias. Revista Brasileira de Educação, Rio de Janeiro, n. 17, p.40-49, 2001. Disponível em: <http://www.scielo.br/pdf/rbedu/n17/n17a03.pdf. $>$. Acessado em: 20 out. 2014.

MOREIRA, Plinio Cavalcanti et al. Quem quer ser professor de matemática? Zeteyiké, Campinas, v. 20, n. 37, p. 11-34, 2012.

MOREIRA, Plinio Cavalcanti; CURY, Helena Noronha; VIANNA, Carlos Roberto. Por que análise real na licenciatura? Zetetiké, Campinas, v. 13, n. 23, p. 11-42, jan./jul. 2005.

NOGUEIRA, Maria Alice; CATANI, Afrânio Mendes (Org.). Pierre Bourdieu: escritos de educação. Petrópolis: Vozes, 2001.

NOGUEIRA, Maria Alice; NOGUEIRA, Cláudio Marques Martins. Bourdieu \& a Educação. 3. ed. Belo Horizonte: Autêntica, 2009. 
NOLAN, Kathleen. Dispositions in the field: viewing mathematics teacher education through the lens of Bourdieu's social field theory. Educational Studies in Mathematics, Netherlands, v.80, p.201-215, 2012.

\section{PASSOS, Caroline Mendes. Condições de produção e legitimação da} etnomatemática. 2017. 226p. Tese (Doutorado em Educação) - Centro de Ciências Humanas, Universidade Federal de São Carlos, São Carlos, 2017.

\section{QUEIROZ, Nilza Maria Cury. Praxiologia e representação social sobre formação} de professores nas licenciaturas de UFPI. 2011. 296 f. Tese (Doutorado em Educação) - Centro de Ciências Sociais Aplicadas, Universidade Federal do Rio Grande do Norte, Natal, 2011.

ROLKOUSKI, Emerson. História de vida de professores de Matemática. Bolema, Rio Claro, n. 30, p.63-88, 2008. Disponível em: <http://www.periodicos.rc.biblioteca. unesp.br/index.php/bolema/article/view/1786/1572> . Acessado em: 28 out. 2014.

SILVA, Circe Mary Silva da. O Impa e a comunidade de matemáticos no Brasil. Cadernos de pesquisa, São Paulo, v. 39, n.138, p. 897-917, 2009.

SILVA, Marilda. O habitus professoral e o habitus estudantil: uma proposição acerca da formação de professores. Educação em Revista, Belo Horizonte, v. 27, n. 3, p. 335-360, 2011. Disponível em: <http://www.scielo.br/pdf/edur/v27n3/v27n3a16.pdf.>. Acessado em: 20 out. 2014.

. O habitus professoral: o objeto dos estudos sobre o ato de ensinar na sala de aula. Revista Brasileira de Educação, Rio de Janeiro, nº 29, p.152-163, 2005. Disponível em: <http://www.scielo.br/pdf/rbedu/n29/n29a12.pdf. $>$. Acessado em: 20 out. 2014.

SOARES, Luisa de Marillac Ramos. Habitus, representações sociais e a construção do ser professora da educação infantil da cidade de Campina Grande-PB. 2011. 189 f. Tese (Doutorado em Educação) - Centro de Ciências Sociais e Aplicadas, Universidade Federal do Rio Grande do Norte, Natal, 2011.

SOBRINHO, Domingos Moises. Habitus, campo educacional e a construção do ser 
professor da educação básica. Revistainter-legere, Natal, n. 9, p.189-205, 2011. Disponível em: <http://www.cchla.ufrn.br/interlegere/09/pdf/09es11.pdf. >. Acessado em: 28 out. 2014.

VILELA, Denise Silva. Matemática nos usos e jogos de linguagem: ampliando concepções na Educação Matemática. 2007. 260p. Tese (Doutorado em Educação) Faculdade de Educação, Universidade Estadual de Campinas, Campinas, 2007.

Recebido em 17/02/2019.

Aprovado em 17/05/2019. 